\title{
Study of different mathematical approaches in determining the dynamic rating of overhead power lines and a comparison with real time monitoring data
}

\author{
P. Castro*, A. Arroyo, R. Martinez, M. Manana, R. Domingo, A. Laso, R. \\ Lecuna \\ University of Cantabria. Department of Electrical and Energy Engineering \\ Av. Los Castros s/n. 39005. Santander, Spain
}

\begin{abstract}
Electricity generation is changing as new, renewable and smaller generation facilities are created, and classic topologies have to accommodate this distributed generation. These changes lead to the creation of smart grids in which advanced generation, information and communication technologies are needed.

Information metering is important, and one of the most important grid parameters to be measured and controlled is the temperature of overhead conductors due to their relation to the maximum allowable sag of the line.

The temperature and current of an overhead conductor and the weather conditions surrounding the cable are measured every 8 minutes for more than a year. With these data, the accuracies of the different algorithms presented in the standards (CIGRE TB601 and IEEE 738) are studied by implementing them in MATLAB ${ }^{\circledR}$.

The use of precise measurements of solar radiation and low wind speeds with ultrasonic anemometers, improves the accuracy of the estimated temperature compared with the real measured conductor temperature. Additionally, using dynamic algorithms instead of assuming a steady state analysis increases the accuracy. However, an equilibrium between the accuracy and mathematical
\end{abstract}

${ }^{*}$ Corresponding author. Tel.: +34-942202065; fax: +34-942201385. E-mail address: pablo.castro@unican.es 
complexity should be obtained depending on the specific needs.

Keywords: Thermal rating, ampacity, overhead line temperature, weather parameters, real-time monitoring

\section{Introduction}

The current needs of global energy management are increasingly challenging due to the fast changes of our society. The electric sector has to address the addition of new and renewable sources of energy to the energy mix and to be able

5 to include them into the grid, while maintaining the principles of robustness, security and reliability. Electricity generation is also changing, and as new and smaller generation facilities are created, classic topologies have to accommodate the distributed generation [1]. On the other hand, energy consumers are moving from being passive to active by increasing their interactions with energy systems. All of these changes point to the creation of smart grids, in which advanced generation, information and communication technologies are needed [2].

Information metering is one of the critical points of these smart grids, and accurate knowledge of the electric grid state and environmental conditions of the surroundings are crucial for operating the line as efficiently as possible [3]. One of the most important grid parameters to be measured and controlled is the temperature of the overhead conductors due to their relation with the maximum allowable sag of the line.

This paper presents the results of real-time monitoring of the environmental conditions, current and temperature of an overhead power line for more than a 20 year and compares these results with the different algorithms presented in the standards CIGRE TB601 and IEEE $738[4,5]$ to estimate the thermal rating and temperature of the conductor. This study is focused on the influence of the accuracy of the parameters involved in the thermal rating equations and the way in which they are implemented in the algorithms. The MATLAB ${ }^{\circledR}$ software is 25 used to solve the thermal rating and calculate the temperature of the conductor. 


\section{Thermal models and mathematical approaches}

The thermal behaviour of an overhead conductor is obtained as the balance of gained and lost heat due to the weather conditions around the conductor and its electrical load [6]. The main sources of gained heat come from Joule so heating, including magnetic effects, and solar radiation. On the other hand, the principal sources of lost heat are convection and cooling radiation to the surroundings. The detailed expressions that are used to calculate each contribution are obtained from the standard CIGRE Dec. 2014 [4] and explained as follows:

Joule Heating $\left(P_{j}\right)$. The Joule heating gain per unit length for conductors is obtained from:

$$
P_{j}=k_{s k} I^{2} R_{d c}
$$

35 where $k_{s k}$ is the skin effect factor, $I$ is the RMS conductor current and $R_{d c}$ is the direct current resistance per unit length.

Magnetic Heating $\left(P_{m}\right)$. A steel-cored conductor causes heating in the steel core $\left(P_{\text {core }}\right)$ and heating due to the redistribution of the current densities in the layers of non-ferrous wires $\left(P_{\text {redis }}\right)$.

$$
P_{m}=P_{\text {core }}+P_{\text {redis }}
$$

The magnetic effects are only relevant for steel-cored conductors with one or three aluminium layers and high current densities.

Solar Heating $\left(P_{s}\right)$. The solar heating per unit length is estimated by the standard as:

$$
P_{s}=\alpha_{s} D I_{t}=\alpha_{s} D\left[I_{b}\left(\sin (\eta)+\frac{\pi}{2} F \sin \left(H_{s}\right)\right)+I_{d}\left(1+\frac{\pi}{2} F\right)\right]
$$

where $\alpha_{s}$ is the absorptivity of the conductor surface, $I_{t}$ is the global radiation intensity, $\mathrm{D}$ is the outside diameter of the conductor, $\eta$ is the angle of the solar beam with respect to the axis of the conductor, $F$ is the albedo, $H_{s}$ is the solar 
altitude, $I_{d}$ is the diffuse sky radiation to a horizontal surface and $I_{b}$ is the direct solar radiation on a surface normal to the sun's beam. $I_{t}$ can be estimated by considering the worst case situation using its maximum expected value or can 45 be directly measured with a pyranometer.

Convective Cooling $\left(P_{c}\right)$. The convective heat loss can be expressed as a function of the dimensionless Nusselt number $(N u)$ as follows:

$$
P_{c}=\pi \lambda_{f}\left(T_{s}-T_{a}\right) N u
$$

where $\lambda_{f}$ is the thermal conductivity of air, $T_{s}$ is the conductor surface temperature and $T_{a}$ is the ambient temperature. Depending on the type of air flow and speed and direction of wind, different Nusselt correlations are used by the standard.

Radiative Cooling $\left(P_{r}\right)$. Applying the Stefan-Boltzmann law, the heat loss from the conductor due to radiation can be expressed as:

$$
P_{r}=\pi D \sigma_{B} \epsilon_{s}\left[\left(T_{s}+273\right)^{4}-\left(T_{a}+273\right)^{4}\right]
$$

where $\sigma_{B}$ is the Boltzmann constant and $\epsilon_{s}$ is the emissivity of the conductor.

To calculate the estimated conductor temperature using the heating and cooling contributions Eq. (1, 2, 3 and 4), two assumptions can be made, a Steady State Analysis (SSA) or a Time Dependent Analysis (TDA) (Fig. 1). 


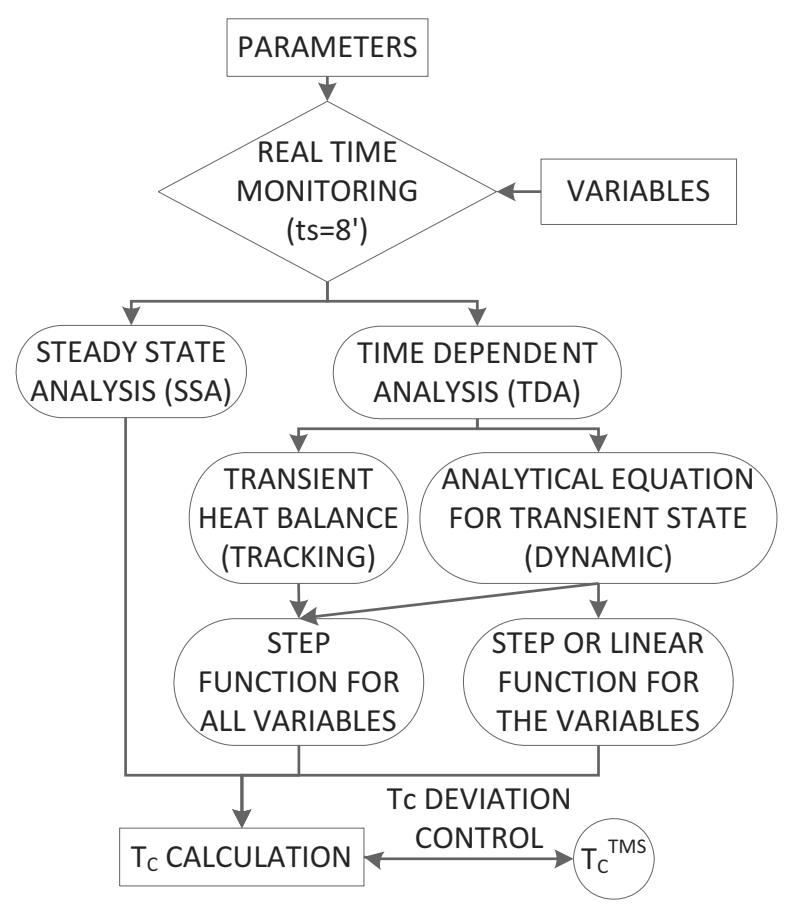

Figure 1: Flow chart of conductor temperature calculations of electrical overhead lines.

The simplest approach to determine the thermal state of the conductor is by assuming that all of the influence variables (wind speed and direction, solar radiation, ambient temperature and current) are constant in an interval of time and when the steady state thermal equilibrium is reached [7]. This leads to a steady state balance in which, the conductor temperature or thermal rating can be obtained, as shown in Eq. (6).

$$
P_{c}+P_{r}=P_{j}+P_{m}+P_{s}
$$

The steady state assumption does not take into account the thermal inertia of the conductor materials, so it is necessary to be sure that all of the variables of interest are constant, at least during the thermal time constant of the conductor. Some of these variables can fit into this condition (ambient temperature and solar radiation), but the most critical ones, which are the wind speed and 
its direction, have large variabilities and are difficult to assume steady state conditions for convection cooling [8]. This is why a time dependent analysis gives a more accurate idea of the thermal behaviour of the conductor (Fig. 1). If a non-equilibrium thermal balance is assumed, Eq. (6) is transformed into:

$$
m c \frac{d T}{d t}=P_{j}+P_{m}+P_{s}-P_{c}-P_{r}
$$

where $m$ is the mass per unit length, $c$ is the specific heat capacity, $d T$ is the temperature increment and $d t$ is the time increment. The thermal inertia of the conductor materials is included. With this approach, both the conductor temperature and thermal rating can be evaluated assuming a time step that is small enough to track the variable of interest.

Finally, an analytical approach obtained by V.T. Morgan from the general heat equation for a homogeneous and isotropic solid can be utilized [4, 9]. This leads to a time response function for each variable which depends on the thermal time constant of the conductor (Fig. 1). Combining the different functions for different variables by assuming the superposition principle, a global time response function can be obtained that characterizes the thermal behaviour of the conductor in dynamic states:

$$
\theta=\theta_{m}-\left(\theta_{m}-\theta_{1}\right) \mathrm{e}^{-t / \tau_{j}} \mathrm{e}^{-t / \tau_{s}} \mathrm{e}^{-t / \tau_{r}} \mathrm{e}^{-t / \tau_{c}}
$$

where $\theta$ is the rise of the average temperature of the conductor above ambient temperature at time $t, \theta_{1}$ is the initial rise of the average temperature of the conductor above ambient temperature at $\mathrm{t}=0, \theta_{m}$ is the asymptotic rise of the average temperature of the conductor above ambient temperature and $\tau_{j}, \tau_{s}, \tau_{r}$ and $\tau_{c}$ are the heating thermal time constants for changes in the current, solar radiation, ambient temperature and wind speed, respectively. The calculation of $\tau$ depends on the type of the variable change.

Now, focusing on the characteristics of the available data (weather variables and line parameters), some distinctions should also be made. For the steady state balance, data should be stable enough to assume this condition, i.e., the variables should not change significantly at least for a period of time equal 
70 to the thermal time constant of the conductor. For time dependent analysis, data should be taken with an adequate resolution to track the transient state and the shape of the transition should also be decided [10]. When using the tracking method, a step change for all variables is assumed every time the data are refreshed and Eq. (7) is solved for a specific time step. Otherwise, when 75 using the dynamic approach with analytical Eq. (8), different transition shapes can be assumed to modify the thermal constant expression. In this paper, a step change and a linear transition are studied and compared (Fig. 1).

\section{Conductor Temperature Calculation}

To calculate the thermal heat balance, real-time data of weather variables

80 (wind speed $u_{w}[\mathrm{~m} / \mathrm{s}]$, wind direction $\phi_{w}\left[^{\circ}\right]$, solar radiation $Q_{s}\left[W / m^{2}\right]$ and ambient temperature $T_{a}\left[{ }^{\circ} \mathrm{C}\right]$ ) were measured with a weather station placed in the electricity tower. Additionally, the current and conductor temperature were measured by a Temperature Measurement Sensor (TMS) attached to the conductor $\left(I_{c}^{T M S}[A]\right.$ and $\left.T_{c}^{T M S}\left[{ }^{\circ} \mathrm{C}\right]\right)$. All of these data were measured every 8 85 minutes $\left(t_{s}=8\right.$ ', sample time) for more than one year (from December 1, 2014, to January 30, 2016) in a $132-\mathrm{kV}$ overhead line with a LA 280 Hawk type conductor [11] located in northern Spain. The main parameters of the studied line are summarized in Table 1. 
Table 1: List of parameters.

\begin{tabular}{ll}
\hline \hline Parameters & Description \\
\hline$D=0.0218 \mathrm{~m}$ & Outside diameter of conductor \\
$D_{1}=0.008 \mathrm{~m}$ & Core diameter \\
$y=622 \mathrm{~m}$ & Altitude \\
$\phi=43^{\circ}$ & Latitude \\
$\delta_{l}=31^{\circ}$ & Line angle \\
$F=0.1$ & Albedo \\
$N_{s}=1$ & Clearness Ratio \\
$\alpha_{s}=0.5$ & Absorptivity \\
$\epsilon_{s}=0.5$ & Emissivity \\
$m_{s}=0.319 \mathrm{~kg} / \mathrm{m}$ & Steel mass per unit length \\
$m_{a}=0.722 \mathrm{~kg} / \mathrm{m}$ & Aluminium mass per unit length \\
$c_{s, 20}=460 \mathrm{~J} / \mathrm{kgK}$ & Specific heat capacity of steel at $20{ }^{\circ} \mathrm{C}$ \\
$c_{a, 20}=880 \mathrm{~J} / \mathrm{kgK}$ & Specific heat capacity of aluminium at $20{ }^{\circ} \mathrm{C}$ \\
$\beta_{s}=1 \cdot 10^{-4} 1 / \mathrm{K}$ & Temp. coefficient of steel specific heat capacity \\
$\beta_{a}=3.8 \cdot 10^{-4} 1 / \mathrm{K}$ & Temp. coefficient of aluminium specific heat capacity \\
$\lambda_{a}=240 \mathrm{~W} / \mathrm{mK}$ & Aluminium thermal conductivity \\
$K_{s k}=1.025$ & Skin factor \\
$R_{20}=0.1194 \Omega / \mathrm{km}$ & Conductor resistivity per unit length at $20{ }^{\circ} \mathrm{C}$ \\
$\alpha_{20}=4.1 \cdot 10^{-3} 1 / \mathrm{K}$ & Linear resistivity coefficient at $20{ }^{\circ} \mathrm{C}$ \\
\hline \hline
\end{tabular}

The conductor temperature $T_{c}$ is calculated using three different analyses in 90 MATLAB $^{\circledR}$ : Steady State Analysis (SSA), Eq. (6), Time Dependent Analysis with a Tracking method (TDA-T), Eq. (7) and Time Dependent Analysis using a Dynamic approach (TDA-D), Eq. (8).

Steady State Analysis (SSA). This analysis uses the line parameters (Table 1 ) and a sample time $t_{s}=8^{\prime}$. Initially, the estimated conductor temperate $T_{c_{j}}$ 95 is assumed to be equal to the ambient temperature $T_{a}$. Then, the steady state equation (Eq. (6)) is iterated, modifying $T_{c_{j}}$ until the steady state temperature 
is reached. Finally, $T_{c_{j}}$ is compared with the conductor temperature measured by the TMS $\left(T_{c}^{T M S}\right)$. This process is repeated for every sample $\left(t_{s}=8^{\prime}\right)$, taking a new initial $T_{c_{j+1}}=T_{c_{j}}$ (Fig. 2).

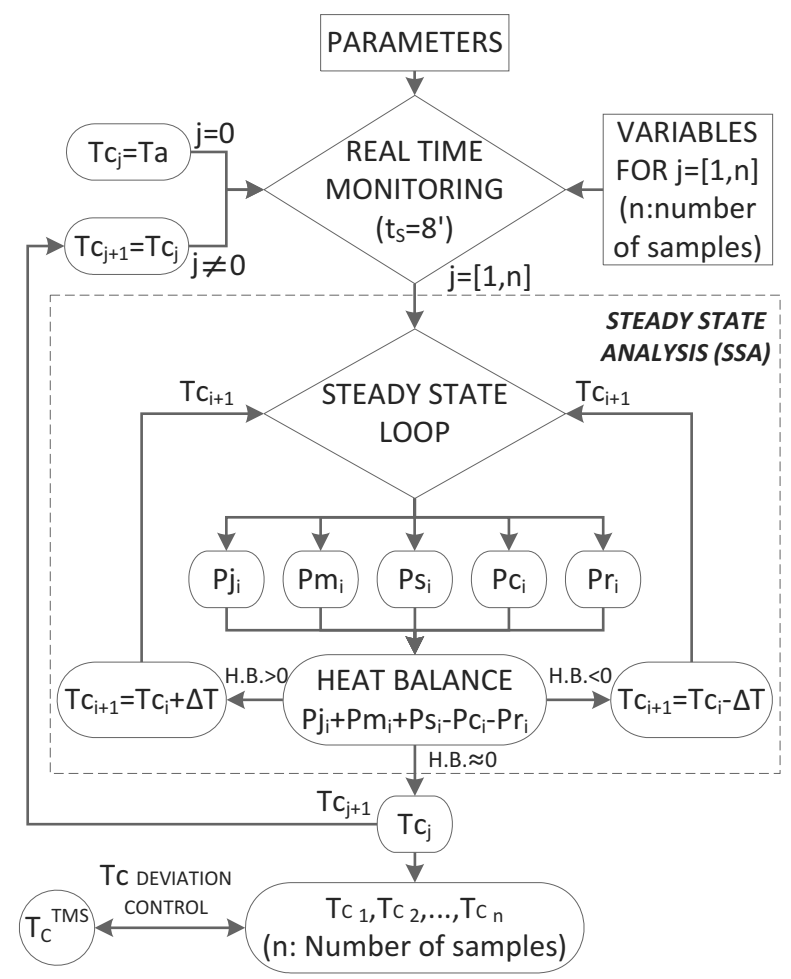

Figure 2: SSA flow chart.

Time Dependent Analysis - Tracking (TDA-T). As in the previous case, variables are recorded every 8 minutes $\left(t_{s}=8^{\prime}\right)$. Each interval is at the same time divided into one second steps $(\Delta t=1 \mathrm{~s})$. Initially, $T_{c_{j=0}}$ is calculated by means of the SSA. Then, the heat balance equation Eq. (7) is tracked until the 8-minute interval is finished. Finally, $T_{c_{j}}$ is compared with the conductor temperature measured by the TMS $\left(T_{c}^{T M S}\right)$ and the next set of data is loaded, taking a new initial $T_{c_{j+1}}=T_{c_{j}}$ (Fig. 3). 


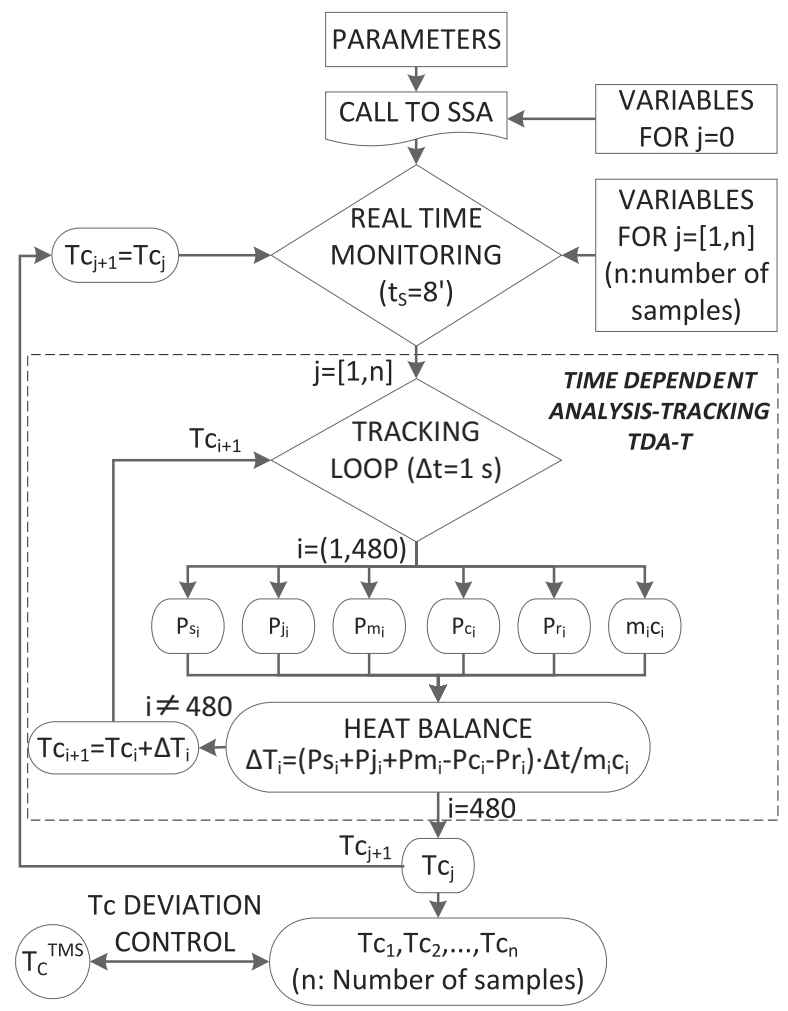

Figure 3: TDA-T flow chart.

Time Dependent Analysis - Dynamic (TDA-D). Initially, $T_{c_{j=0}}$ is calculated by means of the SSA. Then, variables are recorded every 8 minutes $\left(t_{s}=8^{\prime}\right)$. TDA-D uses the analytical equation of Eq. (8) and makes three calls to calculate the different terms of the equation (Fig. 4).

- $\operatorname{SSA}(\mathrm{j})$ to calculate the asymptotic rise of the average temperature of the conductor above ambient temperature $\left(\theta_{m_{j}}\right)$.

- TDA-T(j) to calculate the gain and loss heat associated with sample $\mathrm{j}$ after one second $(\mathrm{i}=1)$.

- TDA-T(j-1) to calculate the gain and loss heat associated with sample j-1 after one second $(\mathrm{i}=1)$. 


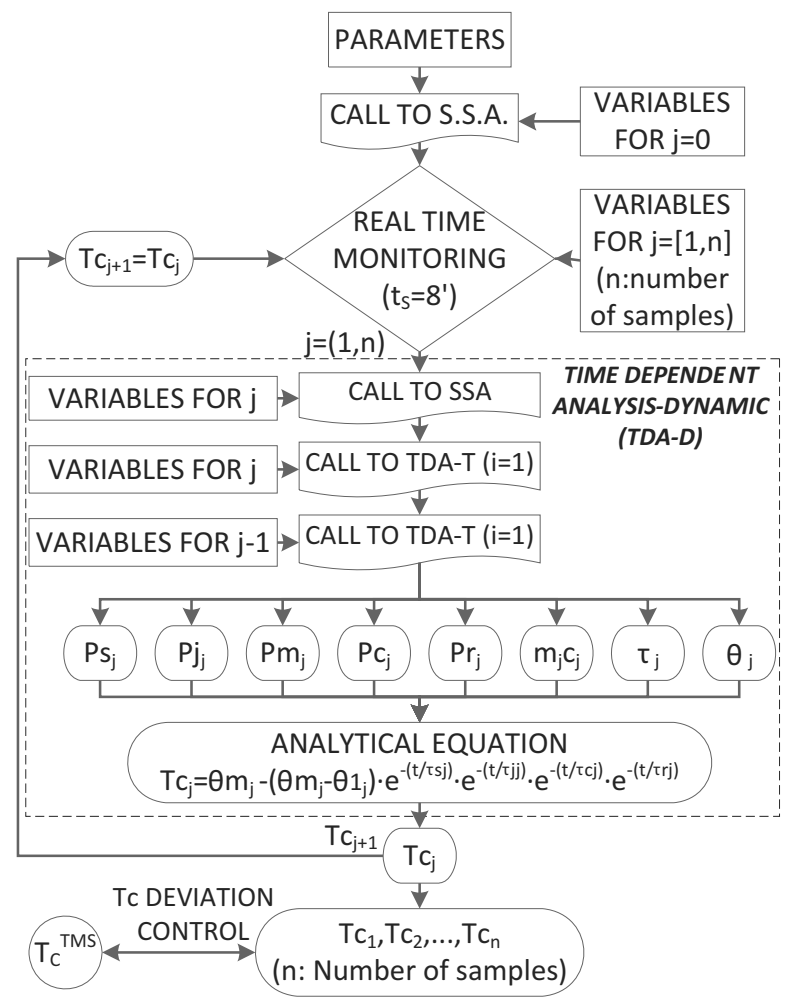

Figure 4: TDA-D flow chart.

\section{Results}

As previously stated, data were recorded for more than one year (from December 1, 2014, to January 30, 2016) in a 132-kV overhead line with a LA 280 Hawk type conductor [11] located in northern Spain. During that time, due to a change in the type of anemometer, two different intervals can be distinguished and compared. In the first period (from December 1, 2014, to September 24, 2015), a cup anemometer was used. In the second period (from September 24, 2015, to January 30, 2016), the cup anemometer was replaced by a 2D ultrasonic anemometer. This made it possible to study the influence of the accuracy and resolution of the wind sensor. Later in this section the results of the different algorithms used are also presented. 
To obtain an idea of the influence of the different variables and the accuracy of the algorithms and to compare this influence with the temperature measured by the TMS, the calculated cases with a deviation of less than $+/-2.5^{\circ} \mathrm{C}$ from the conductor temperature measured by the TMS are analysed. The results for the CIGRE standard algorithms are presented, and in the last part of this section, they are compared with the results obtained for the IEEE standard algorithms.

\subsection{Influence of the wind sensor resolution}

It is commonly known that low speed winds are difficult to measure due to their great variability in direction and the limits of the sensor resolution [12]. This can strongly affect the temperature output of the algorithms, which also loses accuracy at low wind speeds due to the difficulty of having good convection correlations. When using cup anemometers, the region from 0 to $1 \mathrm{~m} / \mathrm{s}$ cannot be well measured because the cups need a minimum speed to start moving. This leads to many values of $0 \mathrm{~m} / \mathrm{s}$ being recorded (more than 600 of the 26,657 values recorded) and can be reasonably thought of as very small winds blowing at a particular speed. In fact, when changed to an ultrasonic anemometer, values lower than $0.1 \mathrm{~m} / \mathrm{s}$ were not recorded in the measured interval.

In practice, this difference means that algorithms using more accurate data for low wind speeds are able to better fit the real temperature measured by the conductor sensor. Fig. 5 shows the temperature deviation from the conductor temperature using cup and ultrasonic anemometers for the tracking algorithm 150 (TDA-T).

In Fig. 5, large deviations for the $u_{w}=0 \mathrm{~m} / \mathrm{s}$ measurements from the cup anemometer are clearly shown, with values overestimating the real conductor temperature by over $20^{\circ} \mathrm{C}$. It is also interesting to note that the cup anemometer measurements tend to overestimate the temperature of the conductor, so in the case of using cup anemometers, these inaccuracies remain on the conservative side. 

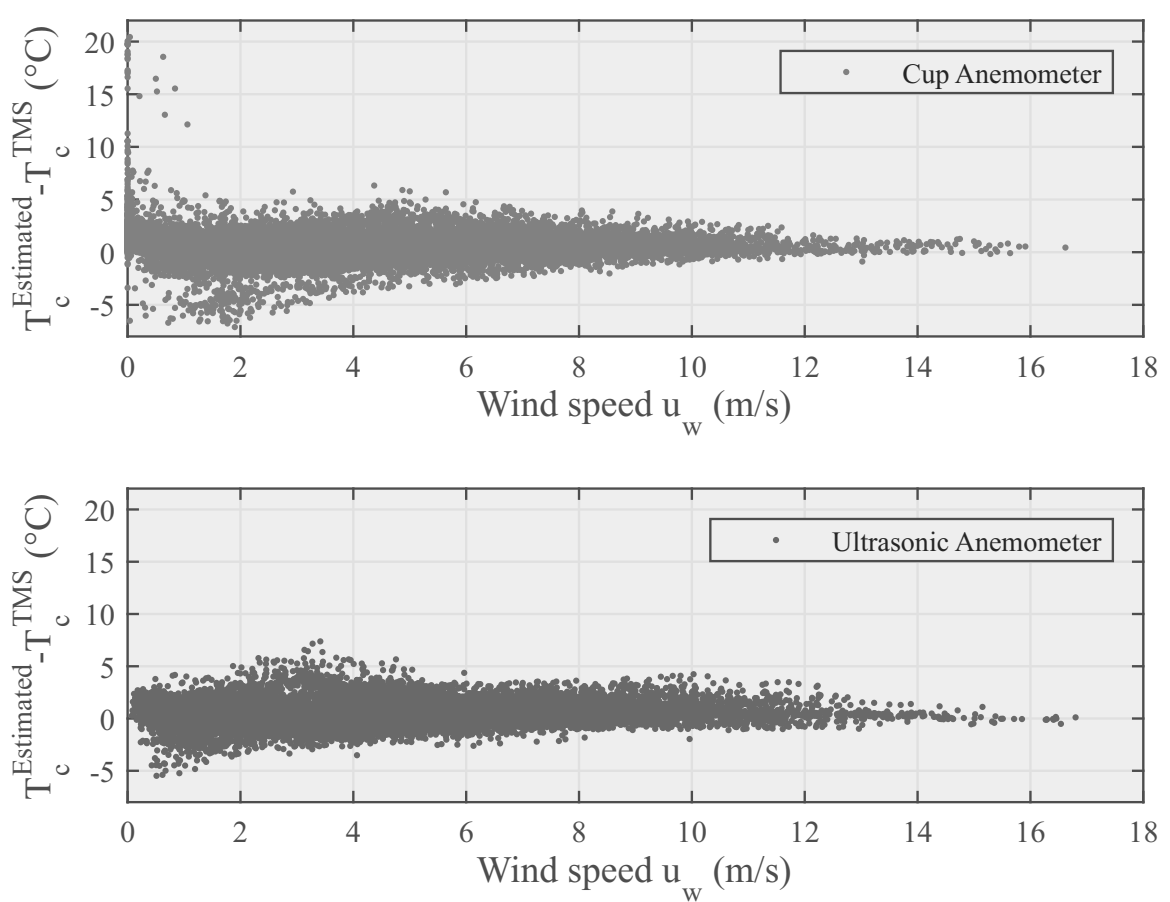

Figure 5: Deviations from the measured conductor temperature vs. the wind speed.

The differences of the percentage of accurate values (percentage of values with a deviation less than $+/-2.5^{\circ} \mathrm{C}$ ) using the cup or ultrasonic anemometer are summarized in Table 2 .

Table 2: Percentage of values with a deviation less than $+/-2.5^{\circ} \mathrm{C}$ using the cup and ultrasonic anemometers.

\begin{tabular}{ccc}
\hline \hline $\begin{array}{c}\text { Wind speed } \\
\text { sensor }\end{array}$ & $\begin{array}{c}\text { Cup } \\
\text { anemometer }\end{array}$ & $\begin{array}{c}\text { Ultrasonic } \\
\text { anemometer }\end{array}$ \\
\hline$\%$ & 92.96 & 96.78 \\
\hline \hline
\end{tabular}

Due to these large differences between the cup and ultrasonic anemometer values, all of the subsequent results are only presented for the time interval recorded with the ultrasonic anemometer (from September 24, 2015 to January $30,2016)$. 


\subsection{Influence of the solar radiation estimation}

CIGRE and IEEE standards give information on how to estimate the solar radiation reaching the conductor as a function of the position and date. This value gives an upper bound of the real radiation present in one specific site and date. If the location where the line is placed usually has cloudy weather (as it is in the case of this study) or has significant shadows, the estimated values may give a high overestimation of the conductor temperature.

If solar radiation is measured with a pyranometer, this information can be included in the algorithm to obtain a better solution. CIGRE (Eq. (3)) and IEEE (Eq. (9)) present similar equations to calculate the heat gained by the conductor due to solar radiation.

$$
q_{s}=\alpha_{s} A^{\prime} Q_{s e} \sin (\theta)
$$

where $A^{\prime}$ is the outside diameter of the conductor and $\theta$ is the angle of the solar beam with respect to the axis of the conductor.

The value of the pyranometer may be interpreted as the total radiation $\left(Q_{s e}\right.$ for IEEE or $I_{t}$ for CIGRE) or the direct beam radiation ( $I_{b}$ for CIGRE). In the second case, the albedo value $F$ should also be indicated and the diffuse radiation $I_{d}$ should be estimated. For this study $F=0.1$, was chosen because the line mainly crosses a forest. The three different options, that is: 1) estimated radiation by CIGRE or IEEE, 2) measured as $I_{t}$ radiation (CIGRE) or $Q_{s e}$ radiation (IEEE) and 3) measured as $I_{b}$ radiation (CIGRE), were used to calculate the conductor temperature and were then compared with the real conductor temperature measured by the TMS. Table 3 summarizes the results indicating the percentage of the values with a deviation less than $+/-2.5^{\circ} \mathrm{C}$ from the TMS measurement for the ultrasonic anemometer values and TDA-T algorithm.

The loss of accuracy using the CIGRE estimated values instead of the measured ones is shown as a $10 \%$ decrease of the deviation temperature values between $+/-2.5 \%$. The use of the pyranometer value as the total radiation $I_{t}$ instead of direct radiation $I_{b}$ has little influence on the percentage of accuracy. 
If the values of the median, maximum overestimation and underestimation and the standard deviation are calculated (Table 3), additional conclusions can be reached.

The lower underestimation using standard estimated radiation is clear due to its conservative approach, which is also shown in its higher overestimation value. Using the pyranometer value as $I_{b}$ gives lower underestimations and similar overestimations than using the $I_{t}$ value for all cases with the cup and ultrasonic anemometer data. This may depend on the value of $F$, and more studies on the algorithm sensitivity to $F$ may be of interest.

Comparing CIGRE and IEEE standards it can be concluded that the latter presents slightly worse estimations when using the pyranometer value as total radiation $\left(I_{t}\right.$ vs. $\left.Q_{s e}\right)$.

Table 3: Percentage of values with a deviation less than $+/-2.5{ }^{\circ} \mathrm{C}$, median, maximum overestimation and underestimation and the standard deviation using estimated radiation, measured as $I_{t}$ or $Q_{s e}$ radiation and as $I_{b}$ radiation.

\begin{tabular}{|c|c|c|c|c|c|}
\hline \multirow{3}{*}{$\begin{array}{c}\text { Radiation } \\
\text { Source }\end{array}$} & \multirow{2}{*}{\multicolumn{2}{|c|}{$\begin{array}{l}\text { Standard } \\
\text { Estimation }\end{array}$}} & \multicolumn{3}{|c|}{ Pyranometer value used as } \\
\hline & & & \multirow{2}{*}{$\begin{array}{c}I_{t} \\
\text { CIGRE }\end{array}$} & \multirow{2}{*}{$\begin{array}{c}Q_{s e} \\
\text { IEEE }\end{array}$} & \multirow{2}{*}{$\begin{array}{c}I_{b} \\
\text { CIGRE }\end{array}$} \\
\hline & CIGRE & IEEE & & & \\
\hline$\%$ & 86,79 & 86,73 & 97,04 & 94,99 & 96,78 \\
\hline Median $\left[{ }^{\circ} \mathrm{C}\right]$ & 0,77 & 0,76 & 0,42 & 0,5 & 0,53 \\
\hline Max. overestimation $\left[{ }^{\circ} \mathrm{C}\right]$ & 9,01 & 9,09 & 7,38 & 8,54 & 7,38 \\
\hline Max. underestimation $\left[{ }^{\circ} \mathrm{C}\right]$ & $-2,53$ & $-2,9$ & $-5,48$ & $-5,46$ & $-4,29$ \\
\hline Standard deviation $\left[{ }^{\circ} \mathrm{C}\right]$ & 1,36 & 1,33 & 0,92 & 1,02 & 0,93 \\
\hline
\end{tabular}

Fig. 6 shows the median of the deviation of the CIGRE estimated temperature from that measured by the TMS (red large line), $50 \%$ of the values (blue box) and the whiskers (black lines) and outliers (small red lines) calculated by 1.5 times the interquartile range. 


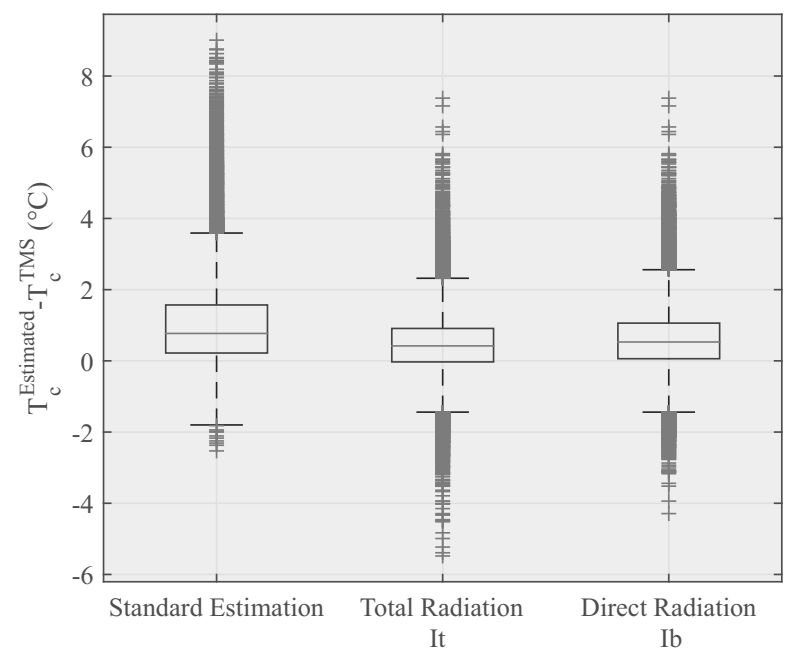

Figure 6: Box plot of the deviation from the measured conductor temperature using CIGRE estimated radiation, measured as $I_{t}$ radiation and measured as $I_{b}$ radiation.

As a representative example, a specific day (September 27, 2015) is presented in more detail for the tracking algorithm (TDA-T) to examine these differences. In Fig. 7, the green, red and yellow lines correspond to the temperature obtained by the CIGRE estimated radiation, measured radiation as total radiation $\left(I_{t}\right)$ and measured radiation as direct radiation $\left(I_{b}\right)$. The black line represents the temperature of the conductor measured by the TMS, and the blue line represents the ambient temperature. Without radiation (during the night), it is obvious that the three approaches obtain the same estimated temperature. However, when the influence of the solar radiation appears the three approaches obtain different estimated temperatures. The solid green line of Fig. 8 is the measured radiation during that day, and the dotted green and purple lines are the values of the estimated radiation by the IEEE and CIGRE standards, respectively. Differences in the estimations of IEEE and CIGRE are observed because IEEE only considers direct radiation in its solar intensity calculations.

For the estimated radiation case, greater differences are shown from approximately 8:00 to 14:00 due to the intervals of cloudy weather in the morning. A 
better fit is obtained in the evening as the estimated radiation becomes closer to the measured radiation. In regards to the use of total or direct radiation, the temperature calculated using the value of the pyranometer as total radiation is slightly lower than using the value as the direct radiation because diffuse radiation and albedo effects are not taken into account.

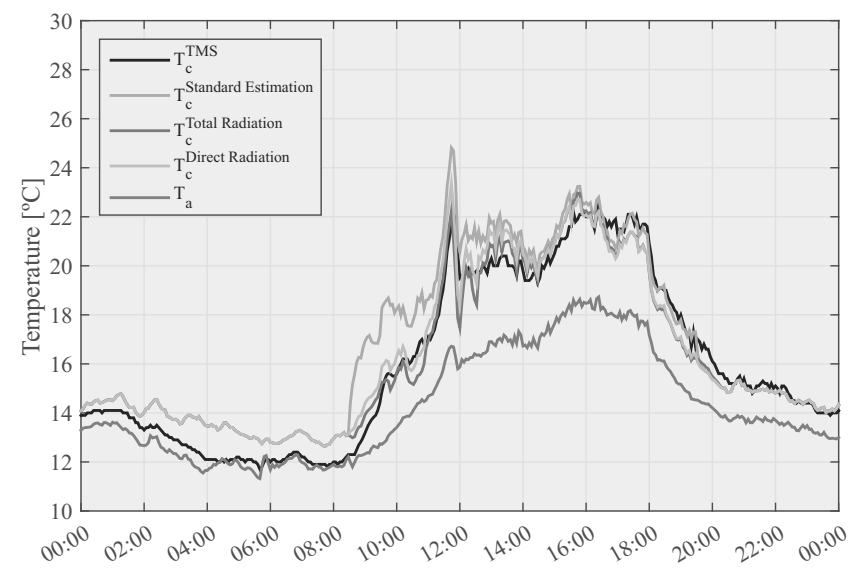

Figure 7: Ambient, conductor and CIGRE estimated temperature for September 27, 2015.

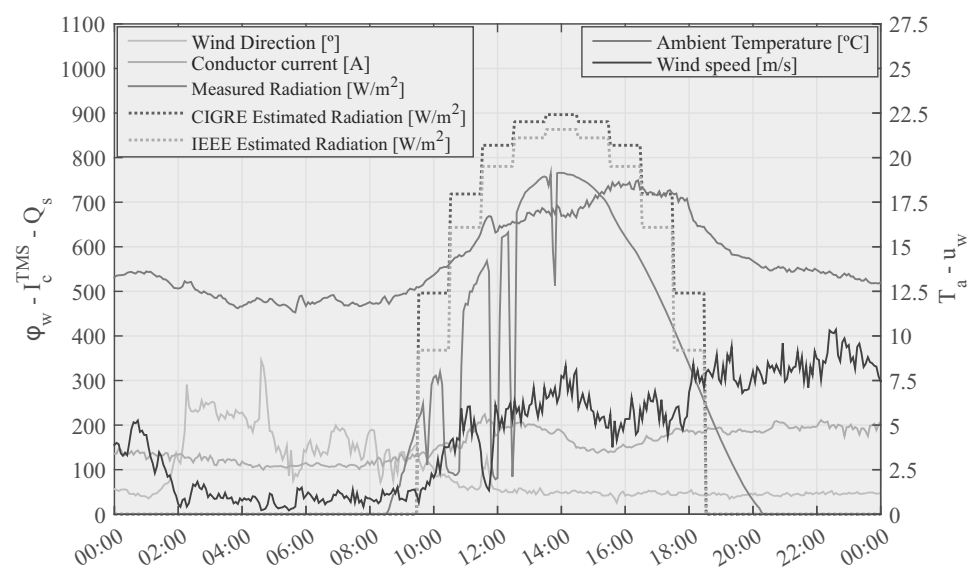

Figure 8: Weather variables for September 27, 2015. 


\subsection{Influence of the type of algorithm}

As previously explained, the conductor temperature was calculated using three different analysis: steady state analyses (SSA), time dependent analysis with a tracking method (TDA-T) and time dependent analysis using the dynamic approach with an analytical equation (TDA-D).

The most accurate option, i.e., the temperature calculated with data from the ultrasonic anemometer and using the measured radiation as the direct radiation $\left(I_{b}\right)$, is studied in this section. To obtain an idea of the accuracy of the algorithms in comparison with the temperature measured by the TMS, the percentage of cases with a deviation lower than $+/-2.5{ }^{\circ} \mathrm{C}$ is calculated and presented in Table 4.

Table 4: Percentage of values with a deviation less than $+/-2.5{ }^{\circ} \mathrm{C}$ using SSA, TDA-T and TDA-D algorithms.

\begin{tabular}{cccc}
\hline \hline & SSA & TDA-T & TDA-D \\
\hline$\%$ & 95.72 & 96.78 & 96.57 \\
\hline \hline
\end{tabular}

The main difference appears between the steady state and two types of time dependent analyses, with an increment of $1 \%$ from steady to transient analyses.

Focusing on the time dependent analysis, the tracking algorithm (TDA-T) seems to be the best fit for the TMS temperature values. When using a more complex algorithm to include the analytical equation (Eq. (8)), (TDA-D) does not increase the accuracy. In fact, the temperatures obtained by TDA-T better match the temperatures of the conductor in the transient periods.

Combining step or ramp responses in the TDA-D does not significantly vary the results. Table 5 shows the type of time responses for each variable and the differences in the percentage. 
Table 5: Percentage of values with a deviation less than $+/-2.5^{\circ} \mathrm{C}$ for different types of time responses.

\begin{tabular}{cccccc}
\hline \hline & Current & $\begin{array}{c}\text { Solar } \\
\text { radiation }\end{array}$ & $\begin{array}{c}\text { Ambient } \\
\text { temperature }\end{array}$ & $\begin{array}{c}\text { Wind } \\
\text { speed }\end{array}$ & \\
\hline C. 1 & Step & Step & Step & Step & 96.57 \\
C. 2 & Step & Ramp & Ramp & Ramp & 94.61 \\
C. 3 & Step & Ramp & Ramp & Step & 95.42 \\
C. 4 & Step & Ramp & Step & Ramp & 95.41 \\
\hline \hline
\end{tabular}

Table 6 summarizes the main statistical values for the algorithms used: median, maximum overestimation and underestimation and the standard deviation.

Table 6: Median, maximum overestimation and underestimation and the standard deviation for all of the algorithms used.

\begin{tabular}{ccccccc}
$\begin{array}{c}\text { Type of } \\
\text { algorithm }\end{array}$ & SSA & TDA-T & $\begin{array}{c}\text { TDA-D } \\
\text { (C. 1) }\end{array}$ & $\begin{array}{c}\text { TDA-D } \\
\text { (C. 2) }\end{array}$ & $\begin{array}{c}\text { TDA-D } \\
\text { (C. 3) }\end{array}$ & $\begin{array}{c}\text { TDA-D } \\
\text { (C. 4) }\end{array}$ \\
\hline \hline Median $\left[{ }^{\circ} \mathrm{C}\right]$ & 0.52 & 0.53 & 0.54 & 0.57 & 0.59 & 0.59 \\
Max. Overestimation $\left[{ }^{\circ} \mathrm{C}\right]$ & 9.50 & 7.38 & 6.69 & 5.89 & 5.89 & 5.89 \\
Max. Underestimation $\left[{ }^{\circ} \mathrm{C}\right]$ & -4.32 & -4.29 & -7.22 & -8.80 & -6.84 & -6.84 \\
Standard Deviation $\left[{ }^{\circ} \mathrm{C}\right]$ & 1.00 & 0.93 & 0.97 & 1.19 & 1.05 & 1.05 \\
\hline \hline
\end{tabular}

Fig. 9 represents the median, $50 \%$ of the values and the outliers. 


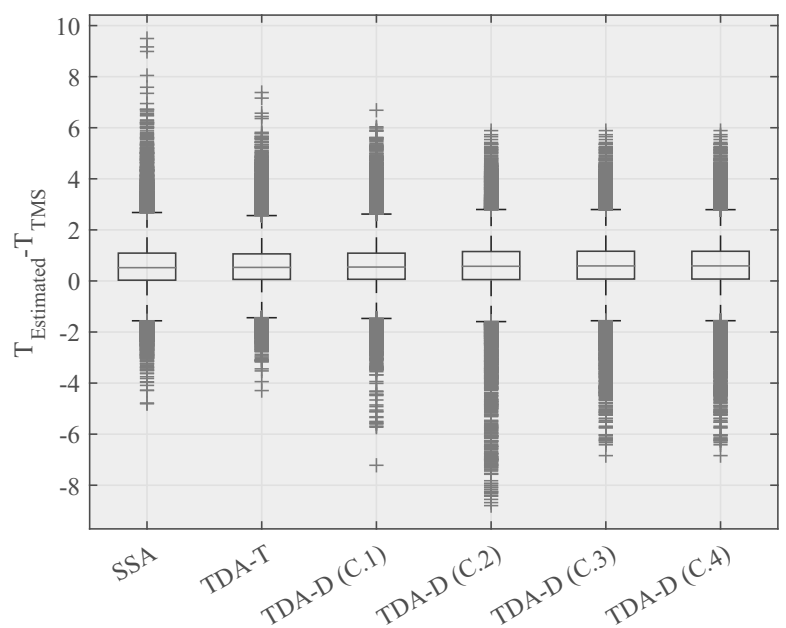

Figure 9: Box plot of the deviation from the measured conductor temperature for all of the algorithms used.

Due to the good results for the tracking algorithm, a sensitivity study of the time step was performed from 0.1 to $120 \mathrm{~s}$ but no differences in the algorithm accuracy were found.

Finally, it is also important to note that the IEEE and CIGRE standards give very similar results in this study, which has also been noticed in previous studies of steady state analysis [13].

Table 7 and Fig. 10 compare both standards. The main differences between both standards are that the percentage of values with a deviation less than $+/$ $2.5{ }^{\circ} \mathrm{C}$ is around $1.5 \%$ higher for CIGRE and that IEEE standard obtains higher overestimation and underestimation. 
Table 7: Percentage of values with a deviation less than $+/-2.5{ }^{\circ} \mathrm{C}$ for IEEE and CIGRE standards.

\begin{tabular}{ccccc}
\hline \hline $\begin{array}{c}\text { Standard } \\
\text { algorithm }\end{array}$ & \multicolumn{2}{c}{ IEEE } & \multicolumn{2}{c}{ CIGRE } \\
$\%$ & SSA & TDA-T & SSA & TDA-T \\
\hline Median $\left[{ }^{\circ} \mathrm{C}\right]$ & 94.25 & 94.94 & 95.72 & 96.78 \\
Max. Overestimation $\left[{ }^{\circ} \mathrm{C}\right]$ & 11.39 & 8.54 & 9.50 & 7.38 \\
Max. Underestimation $\left[{ }^{\circ} \mathrm{C}\right]$ & -5.44 & -5.46 & -4.32 & -4.29 \\
Standard Deviation $\left[{ }^{\circ} \mathrm{C}\right]$ & 1.08 & 1.02 & 1.00 & 0.93 \\
\hline \hline
\end{tabular}

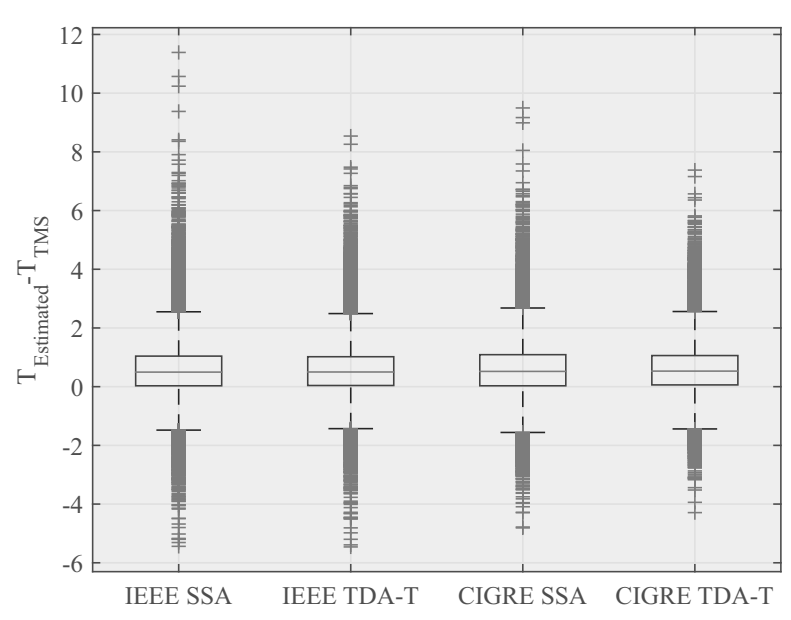

Figure 10: Box plot of the deviation from the measured conductor temperature for IEEE and CIGRE standards.

\subsection{Sensitivity study of sensor measurements}

Due to the variations of the sensor measurements, a Monte Carlo test was made to evaluate their sensitivity. The sensor accuracies provided by the manufacturers are: ambient temperature thermometer $T_{a}+/-0.2^{\circ} \mathrm{C}$, ultrasonic anemometer $u_{w}+/-0.3 \mathrm{~m} / \mathrm{s}$ and $\phi_{w}+/-2^{\circ}$, pyranometer $Q_{s}+/-5 \%$ and power quality analyzer $I_{c}^{T M S}+/-0.1 \%$.

This test was made for the steady state analysis (SSA), using the ultrasonic 
anemometer and including the pyranometer values as the direct radiation $I_{b}$. The first step was to decide the number of Monte Carlo combinations for each set of data. In order to simulate the worst possible scenario, all the sensor measurements were considered to follow a rectangular distribution in their ranges of accuracy. Monte Carlo tests with $n=10,100,1000,10000$ and 100000 combinations of the sensor measurements $\left(u_{w}, \phi_{w}, Q_{s}, T_{a}\right.$ and $\left.I_{c}^{T M S}\right)$ were obtained for one set of data, and the corresponding $n$ conductor temperatures $\left(T_{1} \ldots T_{n}\right)$ were calculated. The mean temperature value for each test $\bar{T}_{1: n}$ and the estimated temperature $T_{\text {estimated }}$ using the original values directly obtained by the sensors were calculated.

Table 8 shows the average and the maximum positive and negative values of the differences $T_{\text {estimated }}-\bar{T}_{1: n}$. It can be seen that the average of the difference tends to zero as the number of Monte Carlo combinations increases and that the range [minimum-maximum] of this difference does not increase significantly from 1000 to 100000 combinations. This is the reason why a 1000 Monte Carlo combinations test was chosen to evaluate the sensitivity of the sensors.

\begin{tabular}{c|ccc} 
Table 8: Sensitivity study of sensors using Monte Carlo method. \\
\hline \hline $\begin{array}{c}\text { Number of } \\
\text { combinations } n\end{array}$ & \multicolumn{4}{|c}{$T_{\text {estimated }}-\bar{T}_{1: n}\left[{ }^{\circ} \mathrm{C}\right]$} \\
\hline 10 & -0.0706 & -0.3552 & 0.2137 \\
100 & -0.0330 & -0.4284 & 0.3418 \\
1000 & -0.0077 & -0.4355 & 0.4521 \\
10000 & -0.0070 & -0.4680 & 0.4338 \\
100000 & -0.0070 & -0.5077 & 0.4670 \\
\hline \hline
\end{tabular}

Then, the 1000 combinations Monte Carlo test was run for all the set of data. The temperature standard deviations $\left(\sigma_{T_{1: 1000}}\right)$ for each set of data were calculated and added as a correction to the estimated conductor temperatures $T_{\text {estimated }}$. In this case, the percentage of values with a difference less than +/$2.5{ }^{\circ} \mathrm{C}$ from the measured temperature $T_{T M S}$ was $94.17 \%$. If these standard 
deviations were subtracted instead, the percentage of these values was $96.85 \%$. Both values are similar to the result $95.72 \%$ presented in Table 4 where the sensor variations were not taken into account.

\section{Conclusions}

The temperature and current of an overhead conductor and the weather conditions surrounding the cable were measured every 8 minutes for more than one year. With these data, the accuracies of different algorithms presented in the standards $[4,5]$ were studied by implementing them in MATLAB ${ }^{\circledR}$.

One result was the large difference in the accuracy of the estimated temperature using cup or ultrasonic anemometers. Although the cup anemometer gave an overestimation of the conductor temperature, it introduced a large deviation between the estimated and measured temperatures in the presence of low winds. The percentage of values with a deviation less than $+/-2.5{ }^{\circ} \mathrm{C}$ was $92.96 \%$ for the cup anemometer and $96.78 \%$ for the ultrasonic anemometer. Thus, ultrasonic anemometers are recommended to be used when possible.

Similar conclusions were found regarding estimated and measured solar radiation. The percentages of values with a deviation less than $+/-2.5{ }^{\circ} \mathrm{C}$ were $86.79 \%$ (CIGRE) and $86.73 \%$ (IEEE) for estimated radiation and $97.04 \%$ (CIGRE) and $94.99 \%$ (IEEE) for measured radiation. Using estimated radiation gave a very high temperature overestimation for cloudy sites; thus, using a pyranometer is highly recommended. The differences in including estimations of albedo $\mathrm{F}$ and diffuse radiation $I_{d}$ were negligible in practice. Comparing CIGRE and IEEE standards, the latter presents slightly worse estimations when using the pyranometer value as total radiation $\left(I_{t}\right.$ vs. $\left.Q_{s e}\right)$.

Steady state analysis gave good results when the recording interval was small enough, but if transitions were to be studied, the tracking time dependent analysis was the best option. More complex algorithms, including time function responses, can increase the amount of mathematical code and the computing time, while not improving the results significantly. The percentages of values 
with a deviation less than $+/-2.5{ }^{\circ} \mathrm{C}$ were $95.61 \%$ (CIGRE) and $94.25 \%$ (IEEE) for the steady state analysis, $96.78 \%$ (CIGRE) and $94.94 \%$ (IEEE) for the tracking algorithm and $96.57 \%$ (CIGRE) for the time dependent algorithm with an analytical equation. Thus, the main differences between both standards are that the percentage of values with a deviation less than $+/-2.5^{\circ} \mathrm{C}$ is around $1.5 \%$ higher for CIGRE and that IEEE standard obtains higher overestimation and underestimation.

The Monte Carlo method was used to analyze the sensor sensitivities for the steady state analysis with 1000 combinations of the sensor measurements. The results were similar to those obtained when the sensor variations were not taken into account.

\section{Acknowledgments}

This work was supported by the Spanish Government under the $\mathrm{R}+\mathrm{D}$ initiative INNPACTO with reference IPT-2011-1447-920000 and Spanish R+D initiative with reference ENE2013-42720-R. The authors would also like to acknowledge Viesgo for its support.

\section{References}

[1] J. Zbojnk, M. Dvok, Power grid simulation model for long term operation planning, Applied Thermal Engineering 70 (2014) $1294-305$.

[2] S. Nykamp, A. Molderink, J. L. Hurink, G. J. Smit, Statistics for pv, wind and biomass generators and their impact on distribution grid planning, Energy 45 (2012) 924 -32. The 24th International Conference on Efficiency, Cost, Optimization, Simulation and Environmental Impact of Energy, (ECOS) 2011.

[3] H. Perez, S. Richards, B. Leyde, When intermittent power production serves transient loads, Applied Thermal Engineering 50 (2013) 1549 -56. 
[4] CIGRE technical brochure 601, guide for thermal rating calculation of overhead lines, December 2014.

[5] IEEE Std. 738-2012, standard for calculating the currenttemperature relationship of bare overhead conductors, 2013. doi:10.1109/IEEESTD . 2013.6692858.

[6] M. W. Davis, A new thermal rating approach: The real time thermal rating system for strategic overhead conductor transmission lines - part I: General description and justification of the real time thermal rating system, IEEE Transactions on Power Apparatus and Systems 96 (1977) 803-9.

[7] V. Morgan, The thermal rating of overhead-line conductors part i. the steady-state thermal model, Electric Power Systems Research 5 (1982) 119 -39 .

[8] CIGRE technical brochure 498, guide for application of direct real-time monitoring systems, June 2012.

[9] V. Morgan, Rating of bare overhead conductors for intermittent and cyclic currents, Electrical Engineers, Proceedings of the Institution of 116 (1969) $1361-76$.

[10] J. Rodriguez, C. Franck, Evaluation of the accuracy of a thermal rating model to estimate the temperature of operational transmission lines, CIGRE Science \& Engineering. Issue 004. (2016).

[11] EN 50182:2001, conductors for overhead lines. Round wire concentric lay stranded conductors, 2001.

365 [12] Cigre technical brochure 299, guide for selection of weather parameters for bare overhead conductor ratings, August 2006.

[13] A. Arroyo, P. Castro, R. Martinez, M. Manana, A. Madrazo, R. Lecuna, A. Gonzalez, Comparison between ieee and cigre thermal behaviour standards and measured temperature on a $132-\mathrm{kV}$ overhead power line, Energies $370 \quad 8(2015) 12391$. 